\title{
Educação em ciências e sua contribuição no estudo dos problemas sociais dos povos indígenas da Amazônia
}

Reginaldo de Oliveira Nunes reginaldonunes@unir.brr orcid.org/0000-0003-4287-9036 Universidade Federal de Rondônia (UNIR), Ji-Paraná, Rondônia, Brasil

Pedro Guilherme Rocha dos Reis preis@ie.ulisboa.pt

orcid.org/0000-0002-9549-2516 Universidade de Lisboa (UL), Instituto de Educação (IE), Lisboa, Portugal

\begin{abstract}
RESUMO
O objetivo desta pesquisa foi refletir sobre a realidade dos problemas sociais enfrentados pelos povos indígenas da Amazônia, bem como a forma que esses problemas podem ser discutidos no currículo de Ciências. Para atingir ao objetivo proposto, foi utilizado questionário composto por oito questões abertas, envolvendo dados sobre os problemas sociais e a educação em Ciências. Os participantes da pesquisa foram 112 (cento e doze) estudantes indígenas em formação no curso de Licenciatura em Educação Intercultural da Universidade Federal de Rondônia. Os resultados demonstram que os problemas sociais diagnosticados têm suas raízes no contato com a sociedade não indígena mediante a processos de disputas por terras, falta de comprometimento dos órgãos governamentais em garantir a demarcação dos territórios indígenas e o não cumprimento do que é previsto na legislação específica. Pode-se observar, que transpor os problemas sociais ao currículo da escola indígena é de fundamental importância às discussões em relação ao que poderá ser feito. Também é necessário buscar soluções que possam beneficiar os povos indígenas, trazendo o bem-estar e bem viver que existiam antes do contato com a sociedade envolvente.
\end{abstract}

PALAVRAS-CHAVE: Povos indígenas. Amazônia. Ensino de Ciências. 


\section{INTRODUÇÃO}

O Brasil possui grande diversidade cultural e linguística. De acordo com o recenseamento de 2010 (IBGE, 2010), os grupos indígenas possuem um total de 817.963 pessoas, o que equivale a $0,47 \%$ da população nacional. Essas pessoas, pertencem a 305 povos, que falam 180 línguas distintas, podendo chegar a 274, devido a inclusão de parcialidades e dialetos (NOVAK et al., 2019).

Os povos indígenas foram e continuam sendo importantes no processo de desenvolvimento desse país. A história do Brasil tem sido marcada por uma relação conflituosa com os povos indígenas. Lutas e processos de escravidão têm conduzido à desvalorização de suas identidades culturais, fortalecendo uma visão distorcida e preconceituosa em relação aos modos próprios com que vivem (SOUZA; GODOY, 2018). Os povos indígenas da floresta Amazônica têm sido destruídos pelo avanço avassalador de outras populações e de culturas bem diferentes das suas.

Nos últimos anos, ocorreram conflitos e surgiram ameaças as terras indígenas, bem como ao conjunto de direitos agregados pela Constituição. Atualmente, os povos indígenas do Brasil, enfrentam inúmeros problemas, quer seja em relação a não demarcação de seus territórios bem como em relação ao preconceito e discriminação pela sociedade envolvente.

Rocha apud Goiris (2018), assinala que a questão dos povos indígenas é um tema que envolve, "a ausência da relativização e de alteridade ou (re)conhecimento do outro", resultando disso, "o predomínio de um exacerbado etnocentrismo, que não permite explicar e entender o 'outro' (o indígena, neste caso) desde uma perspectiva igualitária e democrática", gerando assim preconceito e discriminação por apresentar modos de vida diferentes do tal "estabelecido pela sociedade dominante".

Segundo Perrelli (2008), os indígenas ainda lutam pelo direito à diferença, por uma escola indígena específica, bilíngue e intercultural, já reconhecida pela Constituição Federal de 1988. Na visão da autora, além de ser concebida como espaço para se pesquisar, ensinar e aprender as suas próprias tradições, a escola indígena, deve também constituir um lugar de acesso aos conhecimentos produzidos pela ciência ocidental. É importante que a escola contribua no empoderamento dos povos indígenas, e assim, favoreça a construção do diálogo com outras culturas.

A temática sobre a educação em Ciências vem sendo fonte de estudos e debates há aproximadamente 30 anos, no entanto, nos últimos anos têm merecido crescente importância (BIZZO apud FIGUEIRA, 2019). De acordo com Rodrigues e Rodrigues (2018), em relação as mudanças e avanços científicos no século XIX, "o reconhecimento da importância das ciências foi intensificado na sociedade, provocando mudanças no pensamento e nas ações sociais".

Nesse sentido, é essencial destacar que a educação em Ciências poderia contribuir ao empoderamento de alunos e professores visando a resolução dos problemas de ordem social que atingem a maioria das terras indígenas localizadas na Amazônia.

Implantar práticas educativas requer a compreensão da concepção do currículo como promotor de competências que permitam níveis de tomada de 
decisão de acordo com as necessidades da sociedade (neste caso, indígenas), das características dos alunos (alunos indígenas), e dos contextos específicos e/ou globais em que vivem (seus territórios e os problemas sociais) (REIS, 2013).

Portanto, os professores indígenas, percursores do trabalho, precisam assumir o papel de construtores de um currículo de ciências que auxilie na tomada de decisão sobre os problemas sociais de seus territórios indígenas. A partir desse currículo, é importante que os mesmos possam estabelecer medidas conjuntas (professores, alunos e comunidade) para o empoderamento de seu território, visando consequentemente, a qualidade de vida de todos que nele vivem.

Procura-se, então, refletir sobre a realidade dos problemas sociais enfrentados pelos povos indígenas na Amazônia e de que forma esses problemas podem ser discutidos no currículo do ensino de Ciências nas escolas indígenas.

\section{METODOLOGIA}

Os objetivos da pesquisa estão relacionados com a realização de um diagnóstico sobre os problemas sociais na percepção dos estudantes indígenas em formação no estado de Rondônia, bem como na reflexão sobre como a educação em ciências pode favorecer na discussão e resolução dos problemas.

Visando obter resultados satisfatórios, foi construído um questionário composto por oito questões abertas. Optou-se pelo questionário com questões abertas visando obter dados que realmente pudessem refletir as considerações dos participantes da pesquisa. O questionário envolveu o levantamento de dados sobre os problemas sociais (quais problemas enfrentam em geral, na aldeia, as causas e responsáveis), e sobre os problemas sociais e a relação com a escola (se os problemas eram abordados no currículo da escola, se já tinha sido trabalhado na escola, como o futuro professor poderia trabalhar esses problemas e de que forma a escola poderia contribuir na resolução dos problemas que afetam os povos indígenas).

A amostragem dos dados foi feita por conveniência ou voluntária, sendo incluídos na pesquisa todos os alunos regularmente matriculados no curso e como critérios de exclusão, os que não quiseram participar ou que não estavam presentes no momento da aplicação do questionário. Os participantes da pesquisa responderam ao questionário durante etapa presencial do curso, realizada no semestre 2018/02.

A pesquisa foi classificada como interpretativa, com a utilização de abordagem qualitativa. Procedeu-se, após a aplicação do questionário, a análise dos dados com base na estatística descritiva com o objetivo de detectar tendências nos dados qualitativos analisados.

Na pesquisa, participaram cento e doze estudantes indígenas em formação no Curso de Licenciatura em Educação Básica Intercultural, da Universidade Federal de Rondônia, campus de Ji-Paraná. O curso é organizado levando em consideração o princípio de currículo integrado por meio de temas referenciais articulados em temas contextuais semestrais obrigatórios (disciplinas). Sendo os três primeiros anos dedicados ao ciclo de formação básica e os outros dois anos representam o ciclo de formação específica (DEINTER, 2019). O curso teve seu primeiro vestibular 
diferenciado no ano de 2009, e conta hoje com três turmas concluídas e com quatro turmas em andamento.

Os participantes da pesquisa, pertencem a vinte e sete etnias indígenas, residentes em 21 terras indígenas, localizadas nos estados de Rondônia, Acre e Mato Grosso. As etnias mais representativas foram Suruí (15,2\%), seguido de Wari' $(10,7 \%)$, Arara e Karitiana $(9,8 \%$, cada), Zoró $(8,9 \%)$, entre outras, conforme pode ser visualizado na figura 01.

Os participantes das pesquisa representam um universo de $66,1 \%$ do gênero feminino e 33,9\% do gênero masculino, provenientes da faixa etária compreendida entre os 25 a 29 anos (27,7\%), seguido de 30 a 34 anos (24,1\%), 20 a 24 anos $(21,4 \%), 35$ a 39 anos (14,3\%), 40 a 44 anos $(9,8 \%), 45$ a 49 anos $(0,9 \%)$ e não informou a idade (1,8\%). Quanto ao estado civil, $44,6 \%$ são solteiros, $26,8 \%$ casados, 19,6\% vivem em união estável, 0,9 divorciados e $8,0 \%$ não responderam.

Figura 1 - Número de participantes da pesquisa por etnias indígenas

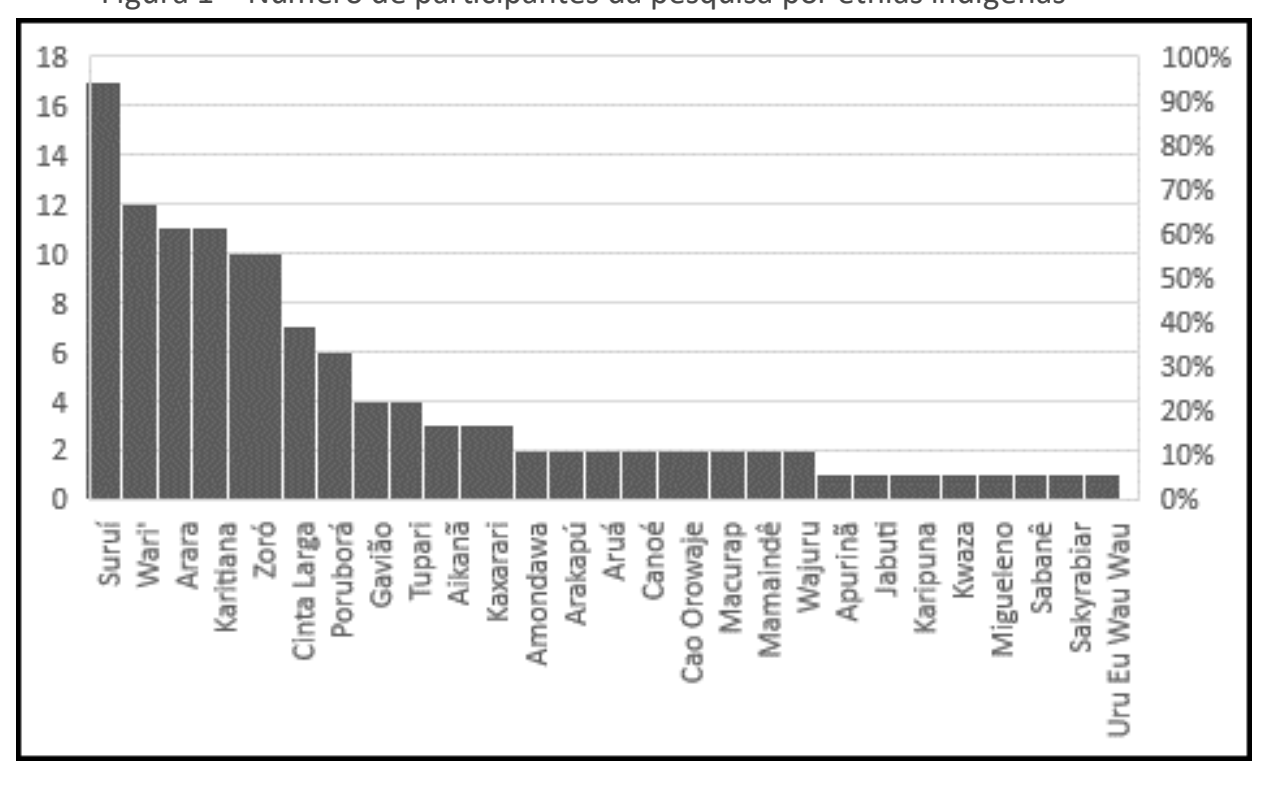

Fonte: Autoria própria (2019).

Levando em consideração os aspectos éticos da pesquisa científica, o projeto foi aprovado pela Comissão de Ética do Instituto de Educação da Universidade de Lisboa, sob o número de registro 3802, em 16 de outubro de 2019.

\section{RESULTADOS E DISCUSSÃO}

Dos estudantes indígenas participantes da pesquisa, 49,1\% são professores e $50,9 \%$ ainda não atuam como professores, no entanto, estão em um curso de formação de professores, visando assumir o protagonismo das atividades docentes nas escolas indígenas de suas aldeias.

Em relação aos que atuam como professores, $27,3 \%$ exercem a função na escola entre 1 e 2 anos, 20,0\% entre 3 a 4 anos, 18,2\% entre 7 e 8 anos, 14,5\% entre 5 e 6 anos, $12,7 \%$ a mais de 10 anos e 7,3\% entre 9 a 10 anos. Em relação aos seguido de agricultores ( $8,8 \%)$, membro da comunidade, agente indígena de saúde 
e assistente administrativo (3,5\% cada), dona de casa e funcionário público (1,8\%, cada).

A principal fonte de renda é proveniente dos salários recebidos (50,9\%), devido grande parte dos participantes serem professores, seguido da agricultura $(25,0 \%)$, do salário de outro membro da família $(5,4 \%)$, da venda de artesanatos $(4,5 \%)$, do recebimento de bolsa família $(2,7 \%)$, da coleta e comercialização da castanha $(2,7 \%)$, e um total de $8,9 \%$ não responderam à questão.

A fonte de renda é responsável pelo sustento das famílias dos entrevistados que são compostas por 1 a 2 pessoas (4,5\%), 3 a 4 pessoas (36,6\%), 5 a 6 pessoas $(39,3 \%), 7$ a 8 pessoas $(17,9 \%)$, e com mais de 8 pessoas $(1,8 \%)$.

A profissionalização docente é a principal fonte de renda nas aldeias, o que representa a importância dos cursos de formação de professores indígenas, garantindo assim a geração de renda nas aldeias. Além do aspecto financeiro, representa também assumir o protagonismo da educação indígena, até então, ocupada, em grande maioria, por professores não indígenas, que não conhecem a realidade da comunidade.

Nesse sentido, Lobo (2018) destaca que no cenário atual da educação escolar indígena, existe a necessidade de uma proposta de ensino diferenciado para os povos indígenas, sendo que essa proposta, somente será efetivada com os próprios indígenas assumindo o protagonismo das atividades docentes nas escolas de suas aldeias.

De acordo com as observações de Perrelli (2008), "o mundo é multicultural", fazendo referência a um território onde coexistem grupos de origem étnica e geográfica diferentes. Complementa ao destacar que a "mobilidade populacional tem colocado em relevo a questão da interação entre grupos culturais distintos". Essas relações entre as culturas podem gerar transformações recíprocas que irão favorecer ou não a continuidade da existência dos mesmos. A autora ainda aponta que a convivência entre as diversas culturas apresenta diferentes formas do multiculturalismo, sendo a preocupação dessa pesquisa voltada ao multiculturalismo conservador. O multiculturalismo conservador é aquele da intolerância, deslegitimação dos saberes, crenças e valores do outro (PERRELLI, 2008), evidenciado neste trabalho, pelos problemas sociais que afetam os povos indígenas na Amazônia.

Portanto, é fundamental que os indígenas assumam esses lugares, tendo em vista, fortalecer a cultura a ter a possibilidade de inserir no currículo da escola, a discussão sobre problemas que afetam seu povo, como no caso, desse trabalho, os problemas sociais.

Os problemas sociais que os povos indígenas enfrentam em seu cotidiano, na perspectiva dos participantes da pesquisa, estão representados na Tabela 1 apresentados a seguir. 
Tabela 1 - Percepção dos participantes da pesquisa sobe os problemas sociais enfrentados pelos indígenas em geral e pelos indígenas na sua aldeia. Ji-Paraná,

Rondônia, 2019

\begin{tabular}{|c|c|c|c|}
\hline \multicolumn{2}{|c|}{ Problemas Sociais - Indígenas em geral } & \multicolumn{2}{|c|}{ Problemas Sociais - Indígenas da Aldeia } \\
\hline Problema & Freq. & Problema & Freq. \\
\hline Alcoolismo & $2,5 \%$ & Alcoolismo & $11,8 \%$ \\
\hline Ameaças e Violência & $8,6 \%$ & Ameaças e Violência & $3,5 \%$ \\
\hline Brigas internas & $1,1 \%$ & Brigas internas & $3,5 \%$ \\
\hline $\begin{array}{l}\text { Demarcação das Terras } \\
\text { Indígenas }\end{array}$ & $5,0 \%$ & $\begin{array}{c}\text { Demarcação das Terras } \\
\text { Indígenas }\end{array}$ & $1,8 \%$ \\
\hline $\begin{array}{c}\text { Desigualdade social / diferença } \\
\text { cultural }\end{array}$ & $1,4 \%$ & $\begin{array}{c}\text { Desigualdade social / diferença } \\
\text { cultural }\end{array}$ & $0,4 \%$ \\
\hline Desvalorização da cultura & $0,7 \%$ & Desvalorização da cultura & $0,4 \%$ \\
\hline $\begin{array}{c}\text { Falta de apoio dos órgãos } \\
\text { governamentais }\end{array}$ & $6,1 \%$ & $\begin{array}{c}\text { Falta de apoio dos órgãos } \\
\text { governamentais }\end{array}$ & $7,9 \%$ \\
\hline Influência de religiões externas & $1,1 \%$ & Influência de religiões externas & $3,1 \%$ \\
\hline $\begin{array}{c}\text { Infraestrutura de acesso às } \\
\text { aldeias }\end{array}$ & $2,5 \%$ & $\begin{array}{l}\text { Infraestrutura de acesso às } \\
\text { aldeias }\end{array}$ & $2,6 \%$ \\
\hline Invasão das terras indígenas & $10,8 \%$ & Invasão das terras indígenas & $9,6 \%$ \\
\hline Luta pela garantia dos direitos & $2,2 \%$ & Luta pela garantia dos direitos & $04 \%$ \\
\hline Pobreza, miséria e fome & $2,5 \%$ & Pobreza, miséria e fome & $0,9 \%$ \\
\hline $\begin{array}{c}\text { Preconceito / discriminação } \\
\text { racial }\end{array}$ & $27,2 \%$ & $\begin{array}{c}\text { Preconceito / discriminação } \\
\text { racial }\end{array}$ & $4,4 \%$ \\
\hline Problemas com saúde indígena & $15,4 \%$ & Problemas com saúde indígena & $19,3 \%$ \\
\hline $\begin{array}{c}\text { Problemas com educação } \\
\text { indígena } \\
\end{array}$ & $10,8 \%$ & $\begin{array}{c}\text { Problemas com educação } \\
\text { indígena }\end{array}$ & $16,2 \%$ \\
\hline \multirow[t]{7}{*}{ Suicídio } & $2,2 \%$ & Casamento com não indígenas & $0,9 \%$ \\
\hline & & $\begin{array}{c}\text { Falta de interesse / apoio do } \\
\text { próprio grupo indígena }\end{array}$ & $2,2 \%$ \\
\hline & & $\begin{array}{c}\text { Falta de respeito aos mais } \\
\text { velhos }\end{array}$ & $0,4 \%$ \\
\hline & & Problemas ambientais na aldeia & $7,9 \%$ \\
\hline & & Prostituição & $0,4 \%$ \\
\hline & & Uso de drogas & $2,2 \%$ \\
\hline & $100 \%$ & & $100 \%$ \\
\hline
\end{tabular}

Fonte: Autoria própria (2019).

Entre os problemas sociais listados pelos participantes da pesquisa em relação aos que acontecem com os povos indígenas em geral e na sua aldeia, quinze deles coincidem. No que se refere aos problemas que afetam os indígenas em geral, o mais representativo foi o preconceito/discriminação racial $(27,2 \%)$, e o mais representativo entre os que afetam os indígenas de suas aldeias está o problema com saúde indígena (19,3\%).

No que tange a esses dados analisados, Santos (2017), discute que é preocupante os casos de preconceito e racismo contra as populações indígenas, sendo esses agravados com o passar dos anos. Os indígenas são reprimidos e excluídos da sociedade onde estão inseridos principalmente, em consequência das campanhas anti indígenas lançadas na política.

Corroborando com essa discussão, Nascimento (2017), destaca que "comportamentos preconceituosas são capazes de alimentar pensamentos e atitudes graves, incentivar a intolerância e até mesmo a violência". No Brasil, esses 
comportamentos se agravam, principalmente, quando autoridades dos pais e outros cidadãos da sociedade civil fazem uso de afirmações como: "índio tem terra demais", "índio não produz nada", "índio é um estorvo para a nação".

Segundo Gomes (2014) existe "um largo repertório de afrontas que compõem e refletem as visões e as atitudes, todas negativas, daquilo que se compreende como preconceito contra o índio brasileiro". As contradições e preconceitos em relação aos povos indígenas estão relacionados a falta de conhecimento e pela "ignorância e no desconhecimento sobre o mundo indígena" (LUCIANO, 2006).

Em relação aos problemas com à saúde indígena, pode-se citar as estruturas de saúde precárias, insumos, medicamentos e equipamentos escassos, alta rotatividade de profissionais, complexidade logística de algumas regiões, transporte de urgência e emergências, entre outros. Além desses fatores, o não reconhecimento das especialidades culturais que permeiam o cuidado em saúde dos povos indígenas é um fator preocupante, não existindo a valorização das "medicinas tradicionais" (GARNELO, 2012; LANGDON, 2016). Outro problema relacionado à saúde indígena é a escassez de alimentos ligado à diminuição ou degradação das áreas de plantio, do pescado disponível nos rios que estão, muitas vezes poluídos por agrotóxicos ou redução das áreas florestais advindas do desmatamento (ROCHA et al., 2019).

Também foi possível observar, que o suicídio é um problema que afetam os indígenas em geral, no entanto, não é descrito como que afeta os indígenas nas aldeias dos participantes. Por outro lado, seis problemas a mais foram citados como os que atingem os indígenas residentes nas aldeias dos entrevistados, sendo eles: casamento de indígena com não indígena, falta de interesse/apoio do próprio grupo indígena, falta de respeito aos mais velhos, problemas ambientais que afetam as terras indígenas, prostituição e uso de drogas.

Na tabela 2, são descritos os parâmetros estabelecidos de resposta em relação ao porquê esses problemas sociais acontecem.

Tabela 2 - Análise dos parâmetros de respostas em relação ao questionamento sobre o porquê os problemas sociais acontecem

\begin{tabular}{c|c|c} 
PARÂMETRO & FA & FR \\
\hline Falta de compromisso/interesse dos órgãos governamentais & 40 & $28,4 \%$ \\
\hline Políticos não comprometidos com as questões indígenas & 23 & $16,3 \%$ \\
\hline Invasão e exploração do território indígena & 14 & $9,9 \%$ \\
\hline Falta de organização e diálogo da comunidade indígena & 13 & $9,2 \%$ \\
\hline Entrada de bebidas alcóolicas na aldeia & 10 & $7,1 \%$ \\
\hline Falta de informação sobre os povos indígenas & 10 & $7,1 \%$ \\
\hline Contato com a sociedade envolvente & 08 & $5,7 \%$ \\
\hline Uacilitação da entrada de não indígenas na Terra indígena & 08 & $5,7 \%$ \\
\hline Interferência de outras religiões na cultua indígena & 05 & $3,5 \%$ \\
\hline Valorização da cultua não indígena em decorrência da própria cultura & 02 & $1,4 \%$ \\
\hline Casamentos com não indígenas & 01 & $0,7 \%$ \\
\hline Falta de interesse dos mais jovens pela escola & 01 & $0,7 \%$ \\
\hline Falta de liderança nas aldeias & 01 & $0,7 \%$ \\
\hline & 141 & $100 \%$ \\
\hline
\end{tabular}


Entre os fatores observados, a falta de compromisso e/ou interesse dos órgãos governamentais foi o mais representativo $(28,4 \%)$, seguido de políticos não comprometidos com as questões indígenas $(16,3 \%)$.

Os dois fatores mais representativos se complementam, pois, a falta de comprometimento e/ou interesse dos órgãos governamentais é o reflexo de políticos não comprometidos com as questões indígenas. Tal fator revela que não se faz cumprir o que foi estabelecido em Lei. Também é observado que não há um interesse pela maioria dos políticos na discussão de novas políticas públicas que assegurem a garantia dos direitos dos povos indígenas.

No cenário atual, a situação é ainda mais complexa, sendo notória a aversão do governo em relação aos povos indígenas e ao meio ambiente. Em sua visão, são um empecilho ao desenvolvimento, pois atrapalham a expansão do agronegócio e a exploração de recursos naturais, principalmente na região Amazônica.

Há de se refletir, que apesar das grandes pressões sofridas nos territórios indígenas, por mineradores, madeireiros, fazendeiros, entre outros, esses territórios são o que podemos chamar de "manchas verdes" na Amazônia. Essa consideração é feita levando em questão o pensamento de preservação dos povos indígenas, que utilizam dos recursos do território somente para a sobrevivência. Tal utilização proporciona harmonia com o ambiente (fauna e flora) e preocupação com a sobrevivência das futuras gerações, que irão depender também desse território para sua existência.

Os indígenas têm esse pensamento preservacionista. Foi pensando nisso, que também foi investigado com os participantes da pesquisa, quem seriam os responsáveis por esses problemas sociais. Com base nas respostas dos participantes da pesquisa foi possível perceber que eles responsabilizam os "não indígenas" $(66,9 \%)$, e os próprios indígenas $(33,1 \%)$, pelos problemas sociais. Entre os "não indígenas", pode-se citar os governantes $(29,7 \%)$, os órgãos governamentais $(19,8 \%)$, os madeireiros $(33,7 \%)$, garimpeiros $(4,0 \%)$, latifundiários $(11,9 \%)$ e os missionários de igrejas $(1,0 \%)$.

Os problemas sociais aqui levantados são um grande desafio aos povos indígenas, que lutam desde a colonização contra um modelo dito "assistencialista", preconceituoso, criminoso e ganancioso. Cabe aos povos indígenas assumirem o protagonismo de seus ancestrais, e continuarem a luta pelos seus direitos. Luta essa que nunca deixou de acontecer.

Além disso, segundo Rocha et al. (2019), é importante que os órgãos públicos exerçam um papel mais relevante na defesa dos direitos indígenas no momento de acirramento de conflitos e mudanças no quadro legislativo-institucional. Esses conflitos visam vulnerabilizar ainda mais as populações indígenas no Brasil, "devido à tendência de priorização da exploração predatória dos bens comuns em detrimento do bem viver que orienta o modo de vida de muitos povos indígenas".

Você acredita que os problemas sociais que aconteceu na sua aldeia são estudados na escola? Esse foi o questionamento visando entender se existe uma relação entre os problemas sociais e o currículo ofertado nas escolas indígenas dos participantes da pesquisa (Figura 2). 
Figura 2 - Disciplinas em que os problemas sociais poderiam ser trabalhados em seus currículos na escola indígena

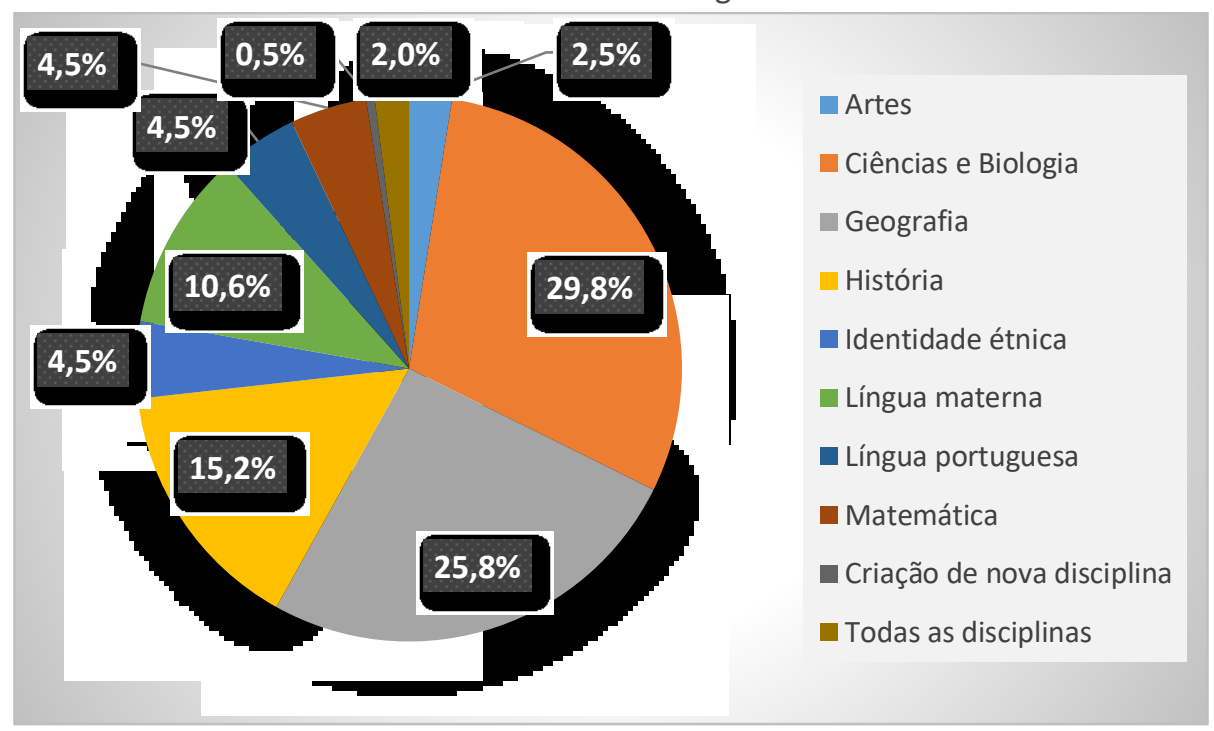

Fonte: Autoria própria (2019).

Nota-se, que $84,8 \%$ acredita que sim, $13,4 \%$ não e $1,8 \%$ não responderam ao questionamento. Entre os que acreditam que sim, foi verificado no currículo de qual disciplina esses problemas sociais diagnosticados poderiam ser trabalhados, sendo a disciplina de Ciências e Biologia a mais representativa (29,8\%), seguida de Geografia $(25,8 \%)$, História $(15,2 \%)$ e língua materna $(10,6 \%)$, entre outras.

Sobre as disciplinas mais representativas, o Referencial Curricular Nacional para as Escolas Indígenas (RCNEI), aborda que a área de Ciências "pode contribuir para melhor compreensão das transformações do mundo pelo ser humano na cultura ocidental, por efeito dos avanços dos conhecimentos científicos e tecnológicos e suas aplicações" (RCNEI, 1998). Aborda também que a área de geografia pode "alargar os conhecimentos já existentes, contribuir para a luta contra os preconceitos e em favor do sentimento de pluralidade e apresentar respostas sobre outros povos e sobre fenômenos da natureza" (RCNEI, 1998).

Em relação à disponibilização de informações sobre os problemas sociais, há de se destacar, segundo Baptista (2010), que "o espaço escolar, e nele o ensino de ciências, muito pode contribuir para alcance dessa meta". A demarcação de conhecimentos no ensino de ciências nas comunidades tradicionais, de acordo com Santilli (2002), "se caracterizam por um conjunto de conhecimentos e práticas que são próprios das suas culturas e úteis para as suas sobrevivências".

No que se refere a relação entre os problemas sociais e a escola, buscou-se conhecer se durante a vida escolar na aldeia dos participantes, já tinha sido trabalhado pelos professores alguns dos problemas sociais que afetam os povos indígenas. Dos participantes da pesquisa, $76,8 \%$ responderam que sim, a temática já havia sido trabalhada na escola, 14,3\% afirmaram que não, 2,7\% não responderam e 6,3\% não estudaram na escola da aldeia. Dos que responderam que havia sido trabalhada, apontaram os temas que foram trabalhados (Tabela 03) bem como as estratégias utilizadas pelos professores para abordar tais temas na escola indígena (Figura 3). 
Tabela 3 - Temas trabalhados na escola indígena sobre os problemas sociais na perspectiva dos participantes da pesquisa

\begin{tabular}{c|c|c} 
TEMAS & FA & FR \\
\hline Invasão da terra indígena & 19 & $24,4 \%$ \\
\hline Cultura indígena & 18 & $23,1 \%$ \\
\hline Preconceito & 15 & $19,2 \%$ \\
\hline Violência & 12 & $15,4 \%$ \\
\hline O território de antigamente & 05 & $6,4 \%$ \\
\hline Respeito ao próximo & 05 & $6,4 \%$ \\
\hline Língua indígena & 04 & $5,1 \%$ \\
\hline
\end{tabular}

Fonte: Autoria própria (2019).

Entre os temas trabalhados pelos professores nas escolas indígenas dos participantes da pesquisa, nota-se que a invasão da terra indígena foi o mais relevante $(24,4 \%)$, seguido da cultura indígena $(23,1 \%)$. Esses fatores, representam problemas sociais, na medida em que a invasão destrói o território, interferindo em seus modos de vida e nos aspectos culturais.

Figura 3 - Estratégias de ensino utilizadas pelos professores das escolas indígenas dos participantes da pesquisa para trabalhar os temas relacionados aos problemas sociais

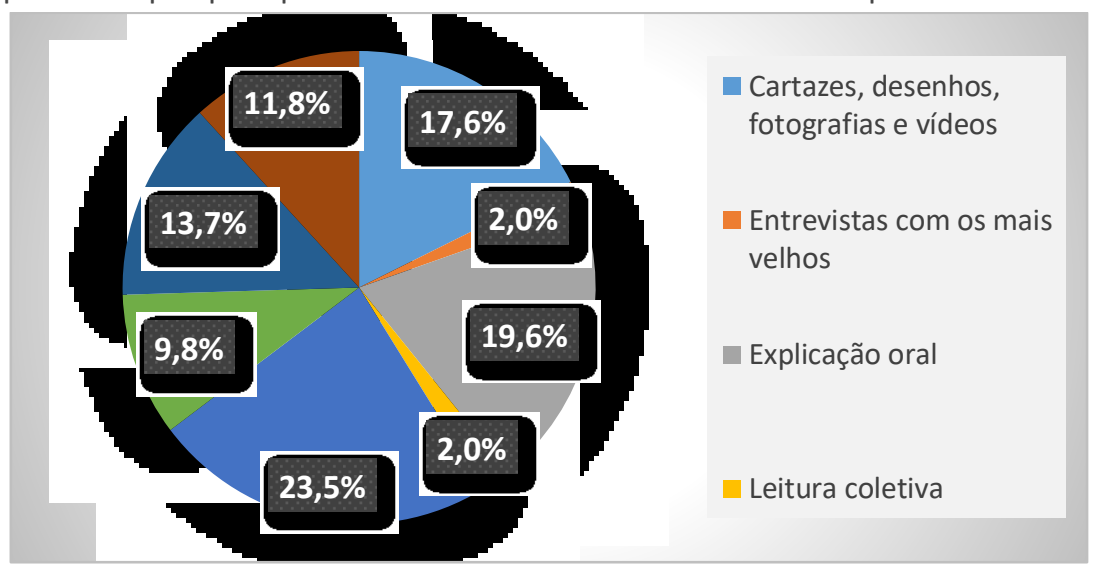

Fonte: Autoria própria (2019).

As estratégias propostas para se trabalhar esses temas nas escolas indígenas pelos professores dos participantes foram palestras $(23,5 \%)$, seguido de explicação oral $(19,6 \%)$, cartazes, desenhos, fotografias e vídeos $(17,6 \%)$, entre outros.

Os participantes da pesquisa (professores em formação e futuros professores), precisam ter a consciência de que ao diagnosticarem os problemas sociais em suas aldeias, terão que transpor essas temáticas para o currículo da escola visando compreender e propor soluções conjuntas com a comunidade visando auxiliar na sua resolução.

Buscou-se, também, conhecer se como professor ou futuro professor, os participantes da pesquisa acreditavam que poderiam trabalhar na escola esses problemas sociais. Dos participantes, $2,7 \%$ não responderam ao questionamento e 97,3 disseram que sim. Entre os que disseram que sim, 65,2\% complementaram suas respostas, apontando que poderiam trabalhar com a conscientização dos alunos sobre os problemas (34,2\%), mostrar a realidade, orientar, alertar e 
oportunizar o conhecimento $(34,2 \%)$, desenvolver atividades na escola $(21,9 \%)$, atividades estas relacionadas a oficinas, aulas de campo, palestras, exemplos, práticas, imagens, desenhos e interdisciplinaridade. Também foram citados a realização de pesquisas $(5,5 \%)$ e procura de alternativas para a resolução dos problemas $(4,1 \%)$.

Em relação a forma com que a escola poderia contribuir à resolução dos problemas sociais que afetam os povos indígenas, os participantes apontaram para a busca de soluções para os problemas junto aos alunos e comunidade indígena $(35,8 \%)$, a conscientização dos alunos e comunidade $(24,6 \%)$, reuniões, palestras e oficinas $(20,9 \%)$ entre outros (Tabela 4$)$.

Tabela 4 - Formas com que a escola indígena poderia contribuir na resolução dos problemas sociais

\begin{tabular}{c|c|c} 
PROPOSTAS & FA & FR \\
\hline Buscar soluções junto aos alunos e comunidade indígena & 48 & $35,8 \%$ \\
\hline Conscientização dos alunos e da comunidade & 33 & $24,6 \%$ \\
\hline Reuniões, palestras e oficinas & 28 & $20,9 \%$ \\
\hline Novas leis e políticas públicas & 07 & $5,2 \%$ \\
\hline Valorização étnica, linguística e cultural & 06 & $4,5 \%$ \\
\hline Inserção dos problemas no currículo da escola & 05 & $3,7 \%$ \\
\hline Criação de documentos visando denúncias aos órgãos públicos & 03 & $2,2 \%$ \\
\hline Produção de material didático de apoio ao professor & 02 & $1,5 \%$ \\
\hline Contratação de profissionais capacitados na área & 01 & $0,7 \%$ \\
\hline Criação de uma disciplina específica para discussão dos temas & 01 & $0,7 \%$ \\
\hline & 134 & $100 \%$ \\
\hline
\end{tabular}

Fonte: Autoria própria (2019).

Observa-se que, a escola é considerada importante aliada nas discussões sobre os problemas sociais que afetam os povos indígenas e que o currículo de Ciências pode estabelecer um diálogo, fazendo um diagnóstico dos problemas junto aos alunos e posteriormente, discutindo e propondo soluções conjuntas.

Segundo Breves et al. (2013), em contexto interétnico e intercultural, os povos tradicionais vêm demonstrando capacidade de resistência, e se engajando em movimentos e ações destinadas à recuperação de sua autonomia e autodeterminação. Esse engajamento visa incorporar conhecimentos e tecnologias do mundo dos não índios, afinando-as com o seu modo de ser e viver, com sua forma de organização política, social e econômica.

\section{CONSIDERAÇÕES FINAIS}

Considerando a autonomia na tomada de decisões em relação a construção do futuro e o empoderamento dos povos indígenas da Amazônia frente aos problemas sociais que os afetam, as escolas indígenas, bem como a educação em Ciências, são fundamentais nesse processo.

Para tanto, existe a necessidade de um diagnóstico dos problemas sociais que interferem no cotidiano das comunidades em que essas escolas estão inseridas e que de alguma forma prejudicam seu bem-estar tanto físico quanto psicológico, 
Transpor esses problemas para o currículo da escola indígena é fundamental para as discussões em relação ao que poderá ser feito, buscando soluções que possam beneficiar a todos, trazendo o bem-estar e bem viver que existiam antes do contato com a sociedade envolvente. Se por um momento, a disciplina de Ciências não seja capaz ainda desse fortalecimento, é possível que por meio de planejamento e da formação de novos professores indígenas, que essas visões sobre os problemas sociais possam refletir no currículo das escolas indígenas. Afinal, as escolas indígenas são consideradas fortes aliadas na busca da autonomia e da afirmação de sua identidade cultural. 


\title{
Science teaching and its contribution in the study of the social problems of indigenous peoples in the Amazon
}

\begin{abstract}
The objective of the research was to reflect on the reality of the social problems faced by the indigenous peoples of the Amazon, as well as the way these problems can be discussed in the Science curriculum. To achieve the proposed objective, a questionnaire composed of eight open-ended questions was used, involving data on social problems and science education. The participants in the survey were one hundred and twelve indigenous students in training at the Degree in Intercultural Education of the Federal University of Rondônia. The results show that the social problems diagnosed have their roots in contact with nonindigenous society through land dispute processes, lack of commitment by government agencies to ensure the demarcation of indigenous territories and non-compliance with what is provided for in specific legislation. It can be observed that transposing social problems into the curriculum of the indigenous school is of fundamental importance to the discussions regarding what can be done. It is also necessary to seek solutions that can benefit indigenous peoples, bringing the well-being and wellbeing that exist before contact with the surrounding society.
\end{abstract}

KEYWORDS: Indigenous peoples. Amazon. Science teaching. 


\section{REFERÊNCIAS}

BAPTISTA, G. C. S. Importância da demarcação de saberes no ensino de ciências para as sociedades tradicionais. Ciências \& Educação, v. 16, n. 3, p. 679-94, 2010. Disponível em: http://www.scielo.br/pdf/ciedu/v16n3/v16n3a12. Acesso em: 04 nov. 2019.

BREVES, N S. P.; MOTA, D. S. M.; MUBARAC SOBRINHO, R. S. Reflexões sobre as concepções de ciências e conhecimento/saberes tradicionais indígenas dos Omágua/Kambeba. Revista Amazônica de Ensino de Ciências, v. 6, n. 11, p. 12336, jul./dez., 2013.

DEINTER. Departamento de Educação Básica Intercultural. Projeto Político Pedagógico. 2019. Disponível em:

http://www.deinter.unir.br/pagina/exibir/2354. Acesso em: 19 dez. 2019.

FIGUEIRA, S. T. S. Teses docentes sobre o processo de ensinar e aprender ciências. ACTIO, v. 4, n. 1, p. 1-25, jan./abr. 2019.

GARNELO, L; Política de Saúde Indígena no Brasil: notas sobre as tendências atuais do processo de implantação do subsistema de atenção à saúde. In: GARNELO, L.; PONTES, A. L. (Orgs.). Saúde indígena: uma introdução ao tema. Brasília: MEC/SECADI, 2012. p. 18-59. Disponível em:

http://bvsms.saude.gov.br/bvs/publicacoes/saude_indigena_uma_introducao_te ma.pdf. Acesso em: 22 out. 2019.

GOIRIS, F. A. O déficit de capital social e a questão dos indígenas em Dourados (MS). Revista Espaço Acadêmico, n. 205, jun. 2018. Disponível em: http://periodicos.uem.br/ojs/index.php/EspacoAcademico/artiche/view/41365. Acesso em: 17 out. 2019.

GOMES, M. P. Índios. In: PINSKY, J. (Org.). 12 faces do preconceito. 11. ed. São Paulo: Contexto, 2014.

IBGE. Instituto Brasileiro de Geografia. Censo Demográfico 2010: características gerais dos indígenas: resultados do universo. Rio de Janeiro: IBGE, 2010.

LANGDON, E. J. Os diálogos de antropologia com a saúde: contribuições para as políticas públicas em saúde indígena. In: LANGDON, E. J.; GRISOTTI, M. Políticas públicas: reflexões antropológicas. Florianópolis: Editora da UFSC, 2016, p. 17-41.

LOBO, M. M. S. Formação de professores indígenas: travessia para um ensino diferenciado na aldeia Canela Ramkokamekrá. 2018. 166 f. Dissertação (Mestrado em Ensino), Universidade do Vale do Taquari, Lajeados, 2018.

LUCIANO, G. S. O índio brasileiro: o que você precisa saber sobre os povos indígenas no Brasil de hoje. Brasília: Ministério da Educação, Secretaria de Educação Continuada, Alfabetização e Diversidade, LACED/Museu Nacional, 2006. 
NASCIMENTO, L. J. De velado a (re) velado: o preconceito contra o índio. Web Revista Sociodialeto, v. 8, n. 22, p. 130-53, abr./jul., 2017. Disponível em: http://sociodialeto.com.br/index.php/socioadileto/artiche/view/78/53. Acesso em: 22 out. 2019.

NOVAK, M. S. J.; MENEZES, M. C. B.; FRANCO, E. S. N. Jogos matemáticos e a formação de professores indígenas nos anos iniciais do ensino fundamental. ACTIO, v. 4, n. 3, p. 430-48, set./dez., 2019.

PERRELLI, M. A. S. Conhecimento tradicional e currículo multicultural: notas com base em uma experiência com estudantes indígenas Kaiowá/Guarani. Ciência \& Educação, Bauru, v. 14, n. 3, p. 381-396, 2008.

RCNEI. Referencial curricular nacional para as escolas indígenas/Ministério da Educação e do Desporto, Secretaria de Educação Fundamental. - Brasília: MEC/SEF, 1998.

REIS, P. Da discussão à ação sociopolítica sobre controvérsias sócio-científicas: uma questão de cidadania. Ensino de Ciências e Tecnologia em Revista, v. 3, n. 1, jan./jun., 2013. Disponível em:

http://repositorio.ul.pt/bitstream/10451/9577/3/DA\%20DISCUSS\%C3\%830\%20\% C3\%80\%20A\%C3\%87\%C3\%830.pdf. Acesso em: 06 jul. 2018.

ROCHA, D. F. da; PORTO, M. F. de S.; PACHECO, T. A luta dos povos indígenas por saúde em contextos de conflitos ambientais no Brasil (1999-2014). Ciênc. Saúde colet., v. 24, n. 2, fev. 2019. Disponível em:

https://www.scielosp.org/scielo.php?script=sci_arttext\&pid=S1413-

81232019000200383. Acesso em: 23 out. 2019.

RODRIGUES, C. S. S.; RODRIGUES, M. A. Refletindo sobre o ensino de ciências com professores dos anos iniciais por meio de uma sequência de ensino investigativo. ACTIO, v. 3, n. 2, p. 58-79, maio/ago. 2018.

SANTILLI, J. A biodiversidade das comunidades tradicionais. In: BESUNSAN, N (Org.). Seria melhor ladrilhar? Biodiversidade como, para que, por quê. Brasília: Editora Universidade de Brasília, Instituto Socioambiental, 2002. p. 89-94.

SANTOS, R. D. Racismo e preconceito contra os Avá-Guarani em Guaíra e Terra Roxa no Paraná. RELACult, v. 3, dez. 2018.

SOUZA, R.; GODOY, K. A educação indígena e as legislações educacionais: um olhar para as políticas indigenistas e indígenas para a educação dos povos Xerentes no estado do Tocantins. Rebento, São Paulo, n. 9, p. 23-52, dez. 2018. 
Recebido: 27 abr. 2020

Aprovado: 18 ago. 2020

DOI: 10.3895/actio.v5n3.12101

Como citar:

NUNES, R. de O.; REIS, P. G. R. dos. Educação em Ciências e sua contribuição no estudo dos problemas sociais dos povos indígenas da Amazônia. ACTIO, Curitiba, v. 5, n. 3, p. 1-16, set./dez. 2020. Disponível em: $<$ https://periodicos.utfpr.edu.br/actio>. Acesso em: XXX

Correspondência:

Reginaldo de Oliveira Nunes

Rua Dr. Edson Holanda, n. 287, Bairro Residencial Araça, Ji-Paraná, Rondônia, Brasil.

Direito autoral: Este artigo está licenciado sob os termos da Licença Creative Commons-Atribuição 4.0

Internacional.

(c) (1) 